\section{Position of Ultrasonography in the scholarly journal network based on bibliometrics and developmental strategies for it to become a top-tier journal}

Sun Huh

Department of Parasitology and Institute of Medical Education, Hallym University College of Medicine, Chuncheon, Korea

Purpose: This study aimed to clarify the present position of Ultrasonography in the scholarly journal network with a variety of bibliometric indicators. Furthermore, developmental strategies for Ultrasonography to become a top-tier journal are suggested.

Methods: The following bibliometric indicators were analyzed: number of citable articles, countries of authors, total cites, impact factor, Hirsch index, authors' countries and source titles of citing articles, and the titles of sources cited by articles in Ultrasonography.

Results: The annual number of citable articles was consistently 40 from 2014 to 2019 . The number of countries of authors increased to 22 in 2018-2019. The numbers of total cites reached 632 in Web of Science, 595 in Scopus, and 552 in the Crossref metadata in 2019. The estimated 2-year impact factor soared from 2.15 in 2016 to 3.20 in 2019. The Hirsch index was 20 in both Scopus and the Web of Science Core Collection. Authors from 76 countries cited Ultrasonography. The number of source titles of citing articles was 668, and the number of source titles cited by articles in Ultrasonography was 1,246.

Conclusion: The above bibliometric results show that Ultrasonography has become a top-tier journal in its field. Ultrasonography furnishes an example of how after changing its language policy to English-only, a local society journal became a highly cited journal in a short period of time. For further development of the journal, adoption of a data-sharing policy is recommended. Furthermore, indexation in MEDLINE should be pursued in the near future.

Keywords: Bibliometrics; Journal impact factor; Language; Metadata; Republic of Korea

\section{Introduction}

Ultrasonography has continued the Journal of Korean Society of Ultrasound in Medicine (Taehan Ch'oǔmp'a Ǔihakhoe chi; ISSN 1015-7085) since 2014 after its language policy was changed to English-only [1]. It has been included in a variety of international indexing databases, as follows: PubMed Central and PubMed since July 2014 [2]; Emerging Sources Citation Index since November 2015 [3]; Scopus since September 2017; and Science Citation Index Expanded (SCIE) since September

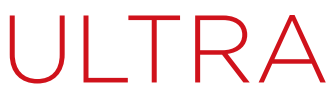

SONO



SPECIAL ARTICLE

https://doi.org/10.14366/usg.20045 pISSN: 2288-5919 - eISSN: 2288-5943 Ultrasonography 2020;39:238-246

Received: March 21, 2020

Revised: April 25, 2020

Accepted: April 27, 2020

Correspondence to:

Sun Huh, MD, Department of Parasitology and Institute of Medical Education, College of Medicine, Hallym University, 1 Hallymdaehak-gil, Chuncheon 24252, Korea

Tel. +82-33-248-2652

Fax. +82-33-256-3426 E-mail: shuh@hallym.ac.kr

This is an Open Access article distributed under the terms of the Creative Commons Attribution NonCommercial License (http://creativecommons.org/ licenses/by-nc/4.0/) which permits unrestricted noncommercial use, distribution, and reproduction in any medium, provided the original work is properly cited.

Copyright @ 2020 Korean Society of Ultrasound in Medicine (KSUM)

How to cite this article:

Huh S. Position of Ultrasonography in the scholarly journal network based on bibliometrics and developmental strategies for it to become a top-tier journal. Ultrasonography. $2020 \mathrm{Jul} ; 39(3): 238-246$. 
2019 [4]. After changing its language to English, the performance of Ultrasonography has been outstanding, with more than 50,000 visits to the journal's website per month. The editor of the journal, Dr. Yu, said that "as our goal is to become a globally leading medical ultrasonography journal, we need effective short- and longterm strategies for increasing the quantity and improving the quality of the content published in Ultrasonography" [5]. It is time to reflect on the achievements of the journal as it has worked towards this goal, and then further developmental strategies may be discussed.

In this article, I would like to present the current position of Ultrasonography in the scholarly journal network based on bibliometrics. Based on the results, I would like to suggest further developmental strategies for Ultrasonography to become an even higher-tier journal. Specifically, the following parameters were analyzed: first, the number of citable and non-citable articles by year; second, the countries of authors who published in Ultrasonography from 2014 to 2019; third, the number of total cites based on the Crossref metadata, Scopus, and Web of Science Core Collection according to year; fourth, the manually calculated 2-year impact factor or equivalent metric based on the Crossref metadata, Scopus, and Web of Science Core Collection according to year; fifth, the Hirsch index based on the Crossref metadata, Scopus, and Web of Science Core Collection; sixth, authors' countries and the source titles of articles that cited U/trasonography based on the Web of Science Core Collection; and, seventh, the titles of sources cited by articles in Ultrasonography.

\section{Materials and Methods}

As this was not a study with human subjects, neither informed consent nor approval of the institutional review board was required.

\section{Study Design and Analysis Methods}

This was a bibliometric analysis based on literature databases.

First, the number of citable and non-citable articles by year was counted on the journal homepage of Ultrasonography. Citable articles included reviews, original articles, and case reports. Second, the countries of authors who published in Ultrasonography from 2014 to 2019 were counted on the journal homepage of Ultrasonography. Third, the number of total cites based on the Crossref metadata, Scopus, and Web of Science Core Collection by year was counted in those three databases. Fourth, the 2-year impact factor (i.e., cites per document over the course of 2 years) based on the Crossref metadata, Scopus, and Web of Science Core Collection according to year was manually calculated as follows.

The definition of the impact factor is as follows: the impact factor of the journal $J$ in the year $X=A / B$, where $A$ is the number of total citations in the year $X$ received by all items published in the journal $\mathrm{J}$ in the years $(X-1)$ and $(X-2)$ and $B$ is the total number of all citable items published in the journal $J$ in the years $(X-1)$ and $(X-2)$.

Fifth, the Hirsch index was calculated based on the Crossref metadata, Scopus, and Web of Science Core Collection. The Hirsch index is defined as "the number of papers with citation number $\geq h$, and it has index $h$ if $h$ of its $N_{p}$ papers have at least $h$ citations each, and the other $\left(N_{p}-h\right)$ papers have $\leq h$ citations each" [6].

Sixth, the citing authors' countries and the source title of the articles that cited Ultrasonography were counted in the Web of Science Core Collection [cited 2020 Mar 16]. Seventh, the types and titles of sources cited by articles in Ultrasonography were counted in the Web of Science Core Collection.

\section{Statistical Analysis}

Descriptive statistics were applied. A comparison with other related journals was described for the impact factor.

\section{Results}

\section{Citable and Non-citable Articles}

As shown in Fig. 1, the number of citable articles, including reviews, original articles, and case reports, was consistently 40 from 2014 to 2019.

\section{Countries of Authors Who Published in Ultrasonography}

The number of countries of authors from 2014 to 2015 was 4; that from 2016 to 2017 was 12; and that from 2018 to 2019 was 22 (Fig. 2, Supplementary Data 1). The proportion of Korean authors

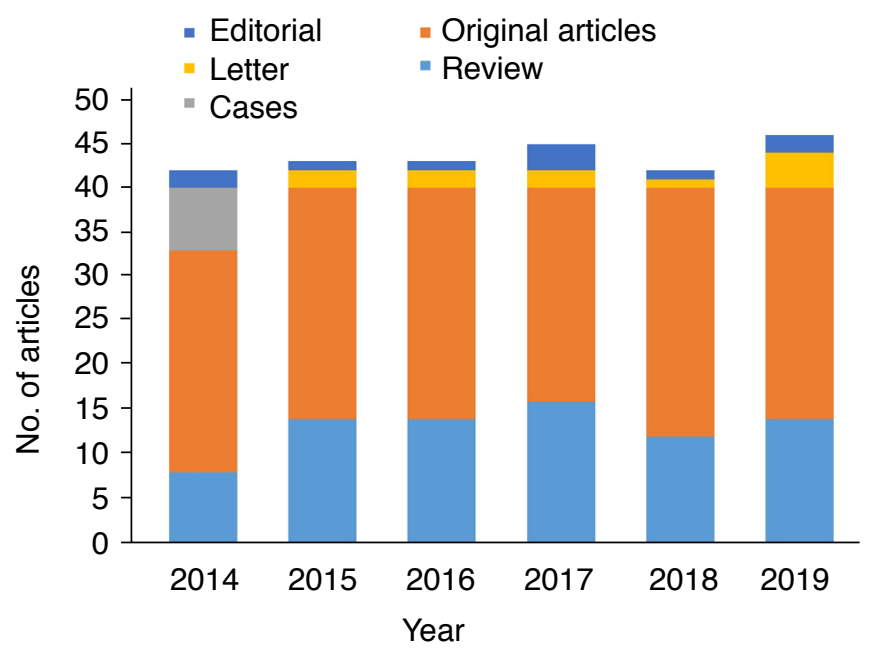

Fig. 1. The number of citable and non-citable articles of Ultrasonography by year. Citable articles: reviews, original articles, and case reports; non-citable articles: letters and editorials. 


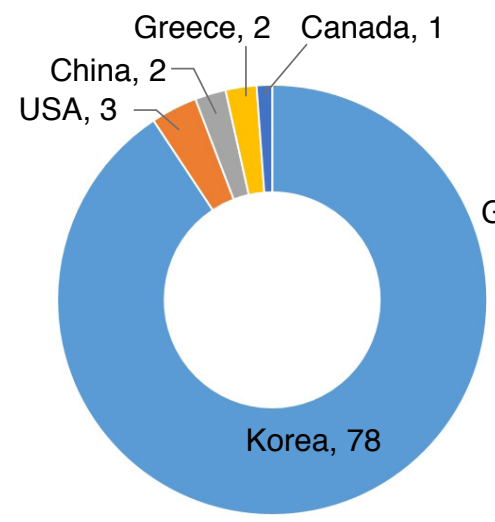

2014-2015

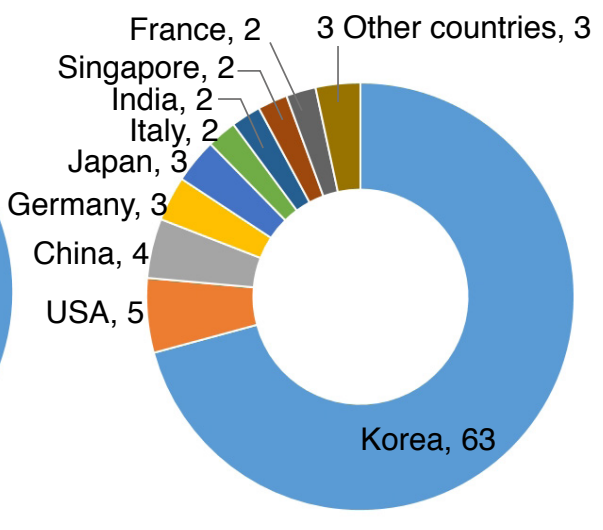

$2016-2017$

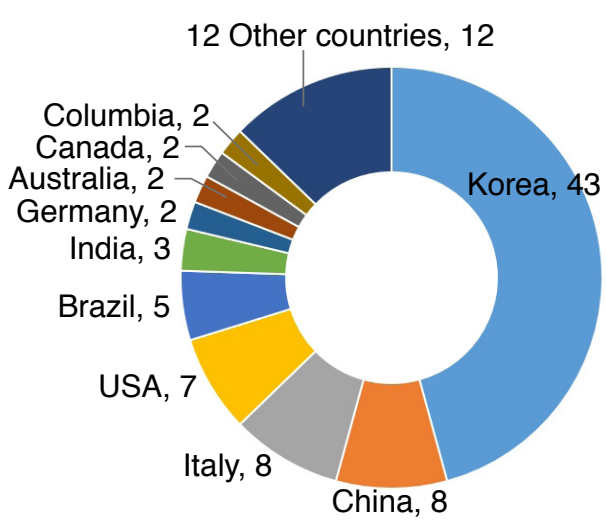

2018-2019

Fig. 2. Countries of authors of Ultrasonography from 2014 to 2019.

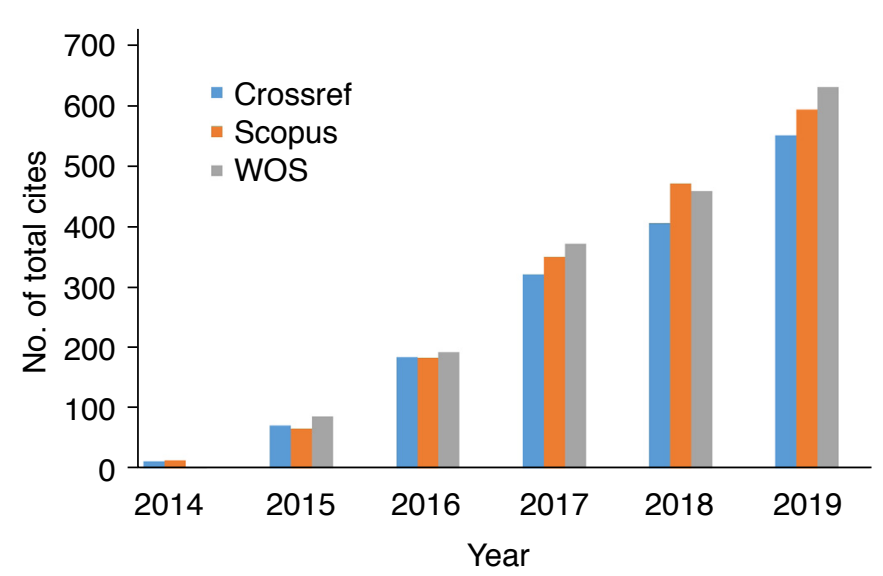

Fig. 3. The number of total cites of Ultrasonography based on the Crossref metadata, Scopus, and Web of Science Core Collection (WOS) by year.

decreased to $45.7 \%$ in $2018-2019$, although it was $90.1 \%$ in 2014-2015.

\section{Total Cites}

The number of total cites of Ultrasonography based on the Crossref metadata, Scopus, and Web of Science Core Collection are presented in Fig. 3 (Supplementary Data 2). It reached 632 in the Web of Science Core Collection, 595 in Scopus, and 552 in the Crossref metadata in 2019.

\section{Two-Year Impact Factor}

The 2-year impact factor and equivalent citation metrics are presented in Fig. 4. In the Web of Science Core Collection, the 2-year

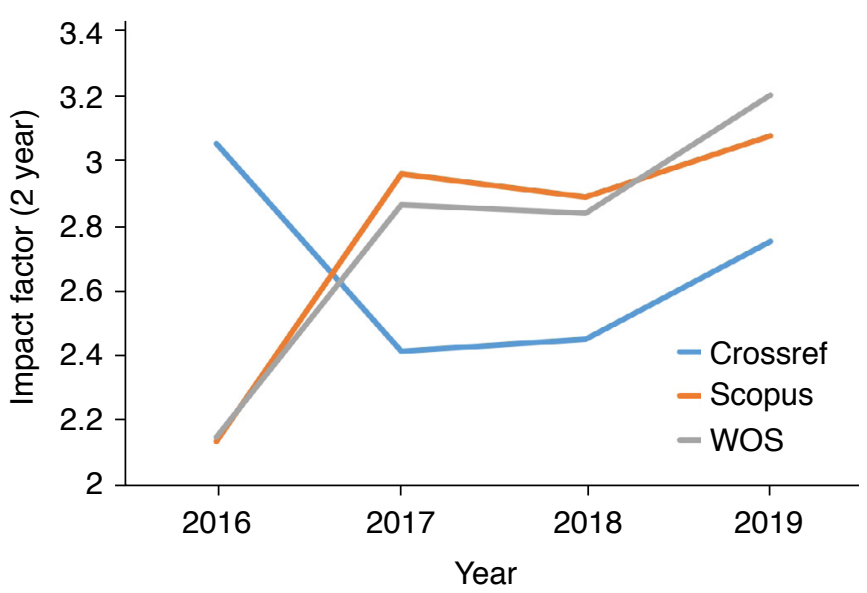

Fig. 4. Impact factor of Ultrasonography based on the Crossref metadata, Scopus, and Web of Science Core Collection (WOS) by year.

impact factor soared from 2.15 in 2016 to 3.20 in 2019. It also changed from 2.136 in 2016 to 3.075 in 2019 based on Scopus, while it decreased from 3.05 in 2016 to 2.75 in 2019 based on the Crossref metadata.

\section{Hirsch Index}

The Hirsch index was 20 based on Scopus (Table 1). The publication types of the 21 most frequently cited articles on Scopus were reviews ( $n=18)$, original articles $(n=2)$, and perspective $(n=1)$. The Hirsch index was also 20 based on the Web of Science Core Collection. The number of review articles out of the 20 most frequently cited articles in the Web of Science Core Collection was 15 , and that of original articles was 5 (Table 2). 


\section{Citing Authors' Countries and Source Titles}

The number of countries of authors who cited Ultrasonography based on the Web of Science Core Collection was 76 (Supplementary Data 3). The top-ranking countries are presented in Fig. 5. Korea, the United States, and China were the top 3 countries. The number of source titles of citing articles was 668 (Supplementary Data 4). The top 9 most frequently citing journals are presented in Fig. 6 .

Types and Titles of Sources Cited by Articles in Ultrasonography The types of sources cited by articles in Ultrasonography from 2014 to 2019 were classified as follows: journals $(n=7,087)$, books ( $n=166)$, conference proceedings ( $n=17)$, web sources $(n=14)$, papers $(n=5)$, and theses $(n=2)$. The number of journals cited by articles in Ultrasonography was 1,246 (Supplementary Data 5). Of these citations, the most frequently listed journal titles are presented in Fig. 7.

\section{Discussion}

\section{Key Results}

The number of citable articles was consistently 40 per year from 2014 to 2015. The number of countries of the authors was 1 in 2014, but soared in 16 in 2019. The total cites reached more than 550 in 3 databases. The 2-year impact factor reached 3.20 in 2019. The Hirsch index was 20 . The journal was cited by authors from 76 countries. The major reference types were journals $(n=7,087)$ and books ( $n=166$ ). The most frequently cited journals were Radiology, American Journal of Radiology, and Journal of Ultrasound Medicine.

\section{Interpretation}

The above results provide a vivid example of the degree to which a local journal could be promoted to a top-tier journal in a short

Table 1. Highly cited articles of Ultrasonography based on Scopus [cited 2020 Mar 16]; Hirsch index: 20

\begin{tabular}{|c|c|c|c|c|c|c|c|}
\hline Rank & Title & Year & Volume & Issue & Page start & Cited by & Document type \\
\hline 1 & $\begin{array}{l}\text { Risk stratification of thyroid nodules on ultrasonography with the French } \\
\text { TI-RADS: description and reflections }\end{array}$ & 2015 & 35 & 1 & 25 & 77 & Review \\
\hline 2 & $\begin{array}{l}\text { Principles and clinical application of ultrasound elastography for diffuse } \\
\text { liver disease }\end{array}$ & 2014 & 33 & 3 & 149 & 64 & Review \\
\hline 3 & $\begin{array}{l}\text { Fusion imaging of real-time ultrasonography with CT or MRI for hepatic } \\
\text { intervention }\end{array}$ & 2014 & 33 & 4 & 227 & 59 & Review \\
\hline 4 & Photoacoustic imaging platforms for multimodal imaging & 2015 & 34 & 2 & 88 & 58 & Review \\
\hline 5 & $\begin{array}{l}\text { Contrast-enhanced ultrasonography: advance and current status in } \\
\text { abdominal imaging }\end{array}$ & 2015 & 34 & 1 & 3 & 58 & Review \\
\hline 6 & Clinical photoacoustic imaging of cancer & 2016 & 35 & 4 & 267 & 54 & Review \\
\hline 7 & Ultrasound elastography for thyroid nodules: recent advances & 2014 & 33 & 2 & 75 & 54 & Review \\
\hline 8 & Ultrasound-guided drug delivery in cancer & 2017 & 36 & 3 & 171 & 45 & Review \\
\hline 9 & Ultrasound elastography for evaluation of cervical lymph nodes & 2015 & 34 & 3 & 157 & 43 & Review \\
\hline 10 & Current status of automated breast ultrasonography & 2015 & 34 & 3 & 165 & 33 & Review \\
\hline 11 & $\begin{array}{l}\text { Diagnostic vascular ultrasonography with the help of color Doppler and } \\
\text { contrast-enhanced ultrasonography }\end{array}$ & 2016 & 35 & 4 & 289 & 31 & Review \\
\hline 12 & $\begin{array}{l}\text { Shear wave velocity measurements using acoustic radiation force impulse } \\
\text { in young children with normal kidneys versus hydronephrotic kidneys }\end{array}$ & 2014 & 33 & 2 & 116 & 30 & Original article \\
\hline 13 & Molecular subtypes and imaging phenotypes of breast cancer & 2016 & 35 & 4 & 281 & 27 & Review \\
\hline 14 & $\begin{array}{l}\text { Thyroid nodules with isolated macrocalcification: malignancy risk and } \\
\text { diagnostic efficacy of fine-needle aspiration and core needle biopsy }\end{array}$ & 2016 & 35 & 3 & 212 & 27 & Original article \\
\hline 15 & $\begin{array}{l}\text { International guidelines for contrast-enhanced ultrasonography: ultrasound } \\
\text { imaging in the new millennium }\end{array}$ & 2016 & 35 & 2 & 89 & 24 & Review \\
\hline 16 & Ultrasonography for nerve compression syndromes of the upper extremity & 2015 & 34 & 4 & 275 & 22 & Review \\
\hline 17 & Current status of musculoskeletal application of shear wave elastography & 2017 & 36 & 3 & 185 & 21 & Review \\
\hline 18 & Altered Doppler flow patterns in cirrhosis patients: an overview & 2016 & 35 & 1 & 3 & 21 & Review \\
\hline 19 & $\begin{array}{l}\text { Transrectal ultrasonography of anorectal diseases: advantages and } \\
\text { disadvantages }\end{array}$ & 2015 & 34 & 1 & 19 & 21 & Review \\
\hline 20 & Shear-wave elastography in breast ultrasonography: the state of the art & 2017 & 36 & 4 & 300 & 20 & Review \\
\hline 21 & Current status of core needle biopsy of the thyroid & 2017 & 36 & 2 & 83 & 20 & Perspective \\
\hline 22 & $\begin{array}{l}\text { The follicular variant of papillary thyroid carcinoma: characteristics of } \\
\text { preoperative ultrasonography and cytology }\end{array}$ & 2015 & 35 & 1 & 47 & 19 & Original article \\
\hline
\end{tabular}


Table 2. Highly cited articles of Ultrasonography based on the Web of Science Core Collections [cited 2020 Mar 16]; Hirsch index: 20

\begin{tabular}{|c|c|c|c|c|c|c|c|}
\hline Rank & Title & Year & Volume & Issue & Page start & Cited by & Document Type \\
\hline 1 & $\begin{array}{l}\text { Risk stratification of thyroid nodules on ultrasonography with the French } \\
\text { TI-RADS: description and reflections }\end{array}$ & 2016 & 35 & 1 & 25 & 72 & Review \\
\hline 2 & $\begin{array}{l}\text { Principles and clinical application of ultrasound elastography for diffuse liver } \\
\text { disease }\end{array}$ & 2014 & 33 & 3 & 149 & 61 & Review \\
\hline 3 & $\begin{array}{l}\text { Fusion imaging of real-time ultrasonography with CT or MRI for hepatic } \\
\text { intervention }\end{array}$ & 2014 & 33 & 4 & 227 & 61 & Review \\
\hline 4 & $\begin{array}{l}\text { Contrast-enhanced ultrasonography: advance and current status in } \\
\text { abdominal imaging }\end{array}$ & 2015 & 34 & 1 & 3 & 56 & Review \\
\hline 5 & Ultrasound elastography for thyroid nodules: recent advances & 2014 & 33 & 2 & 75 & 53 & Review \\
\hline 6 & Photoacoustic imaging platforms for multimodal imaging & 2015 & 34 & 2 & 88 & 50 & Review \\
\hline 7 & Clinical photoacoustic imaging of cancer & 2016 & 35 & 4 & 267 & 46 & Review \\
\hline 8 & Practice guideline for the performance of breast ultrasound elastography & 2014 & 33 & 1 & 3 & 43 & Review \\
\hline 9 & Ultrasound elastography for evaluation of cervical lymph nodes & 2015 & 34 & 3 & 157 & 43 & Review \\
\hline 10 & Ultrasound-guided drug delivery in cancer & 2017 & 36 & 3 & 171 & 37 & Review \\
\hline 11 & $\begin{array}{l}\text { Shear wave velocity measurements using acoustic radiation force impulse in } \\
\text { young children with normal kidneys versus hydronephrotic kidneys }\end{array}$ & 2014 & 33 & 2 & 116 & 34 & Original article \\
\hline 12 & $\begin{array}{l}\text { Diagnostic vascular ultrasonography with the help of color Doppler and } \\
\text { contrast-enhanced ultrasonography }\end{array}$ & 2016 & 35 & 4 & 289 & 31 & Review \\
\hline 13 & $\begin{array}{l}\text { Shear-wave elastography for breast masses: local shear wave speed }(\mathrm{m} / \mathrm{sec}) \\
\text { versus Young modulus }(\mathrm{kPa})\end{array}$ & 2014 & 33 & 1 & 34 & 30 & Original article \\
\hline 14 & Current status of automated breast ultrasonography & 2015 & 34 & 3 & 165 & 28 & Review \\
\hline 15 & $\begin{array}{l}\text { International guidelines for contrast-enhanced ultrasonography: ultrasound } \\
\text { imaging in the new millennium }\end{array}$ & 2016 & 35 & 2 & 89 & 26 & Review \\
\hline 16 & $\begin{array}{l}\text { Usefulness of acoustic radiation force impulse elastography in the differential } \\
\text { diagnosis of benign and malignant solid pancreatic lesions }\end{array}$ & 2014 & 33 & 1 & 26 & 25 & Original article \\
\hline 17 & $\begin{array}{l}\text { Thyroid nodules with isolated macrocalcification: malignancy risk and } \\
\text { diagnostic efficacy of fine-needle aspiration and core needle biopsy }\end{array}$ & 2016 & 35 & 3 & 212 & 24 & Original article \\
\hline 18 & $\begin{array}{l}\text { Application of the Thyroid Imaging Reporting and Data System in thyroid } \\
\text { ultrasonography interpretation by less experienced physicians }\end{array}$ & 2014 & 33 & 1 & 49 & 22 & Original article \\
\hline 19 & Molecular subtypes and imaging phenotypes of breast cancer & 2016 & 35 & 4 & 281 & 22 & Review \\
\hline 20 & Current status of musculoskeletal application of shear wave elastography & 2017 & 36 & 3 & 185 & 21 & Review \\
\hline 21 & Current status of core needle biopsy of the thyroid & 2017 & 36 & 2 & 83 & 20 & Perspective \\
\hline
\end{tabular}

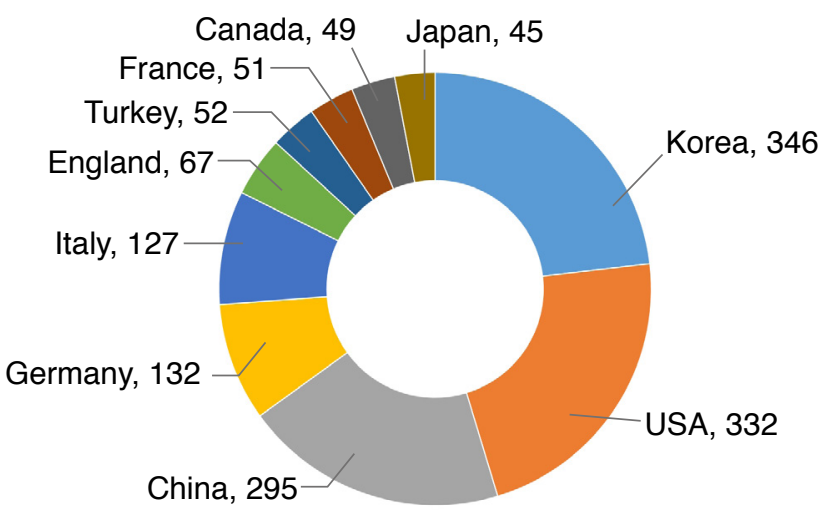

Fig. 5. Top 10 countries from which authors cited Ultrasonography most frequently and their frequency based on the Web of Science Core Collection [cited 2020 Mar 16].

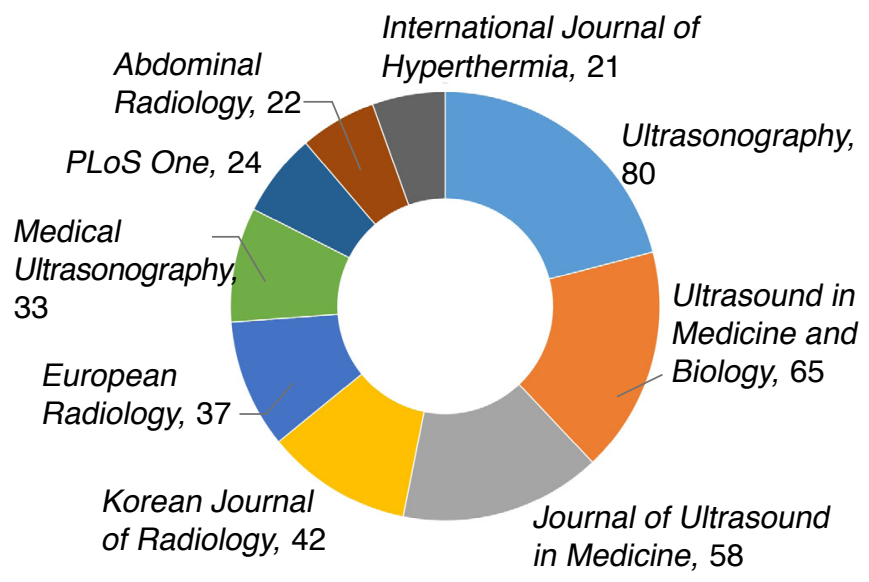

Fig. 6. The journals most frequently citing Ultrasonography in publications from 2014 to 2019 and their frequency based on the Web of Science Core Collection [cited 2020 Mar 16]. 


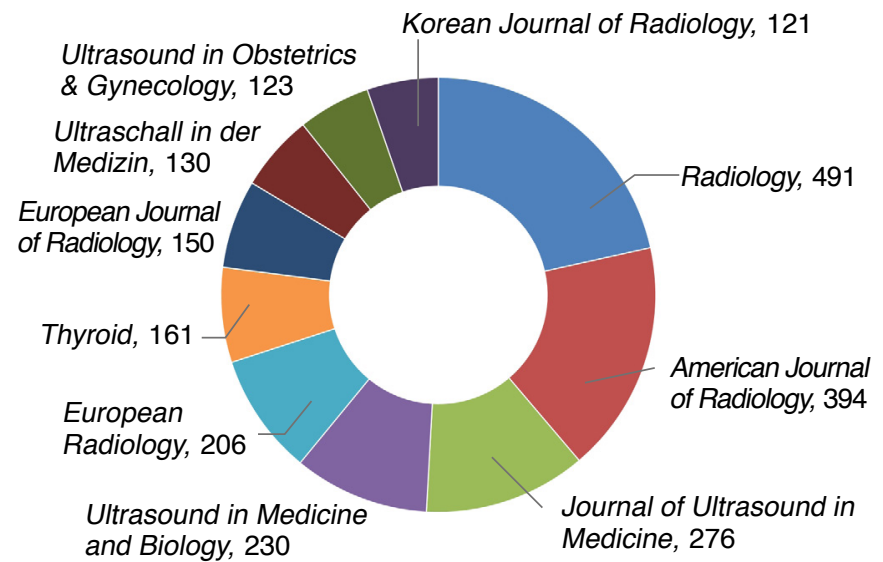

Fig. 7. The top 10 journal titles in references in Ultrasonography and their frequency from 2014 to 2019.

period after changing its language to English. After changing its language policy to English-only, Ultrasonography became indexed in the three most essential literature databases (PubMed, Scopus, and SCIE). Furthermore, its citation frequency soared rapidly. The estimated 2019 Journal Citation Reports (JCR) impact factor of Ultrasonography is 3.2 , which corresponds to a JCR ranking of $72.9 \%$, near the first quartile. In the Radiology, Nuclear Medicine, Imaging category of the Scimago Journal \& Country ranking (https:// www.scimagojr.com/), its 2018 Scientific Journal Rankings (SJR) ranking was 76th out of 328 journals $(76.8 \%)$, meaning that it was in the first quartile. What factors may explain this enormous achievement?

First, the society members' research activities and writing skills are excellent. The level of research conducted by the members of the Korean Society of Ultrasound in Medicine is internationally recognized. Korea is ranked third in the world in terms of the number of presentations at international meetings on ultrasonography. In the early stages of Ultrasonography as an English-language journal, most authors were from Korea; therefore, the citation frequency at the launching stage was dependent on the quality of articles published by Korean authors belonging to the Korean Society of Ultrasound in Medicine. If their competency had not been excellent, it would not have been possible for Ultrasonography to reach its present level.

Second, the two main reasons why this society journal was initially underappreciated were the local language of the main texts and the fact that the journal was not listed in literature databases. After overcoming those shortcomings, Ultrasonography could be widely read by international radiologists, physicians, and researchers. This phenomenon has consistently been observed for other medical journals in Korea. After adopting an English-only policy for publications and being indexed in PubMed, citation frequency began to increase rapidly [7].

Third, Ultrasonography accepted the following digital standards of journal publishing from the time of its launch: journal article tag suite (JATS) XML to be listed in PubMed Central [8]; PubReader and EPUB 3.0 format; digital object identifier (DOI) to provide a persistent direction to the landing page of the journal [9]; the cited-by function; Crossmark and Fundref [10]; the requirement for contributors to provide Open Researchers and Contributors ID (ORCID) profiles [11]; and QR codes [12].

Fourth, the editors and editorial board members have played a superb role in these developments. They introduced an internationallevel editorial policy, including careful review, and firmly adhere to international ethical guidelines, including the Principles of Transparency and Best Practice in Scholarly Publishing, 3rd version $[13,14]$.

Fifth, the society has supported journal publishing and editorial work without any limitations. With the full financial support of the society, the members of the editorial team have been able to demonstrate their high level of competence.

The difference in total cites across the three databases originated from differences in the journals included in each database (Fig. 3). If all Scopus and Web of Science Core Collection journals deposited their reference metadata to Crossref, the frequency count based on the Crossref database would be expected to be the highest. However, many journals have not done so. The same issue arose in the estimation of the 2-year impact factor (Fig. 4). The impact factor equivalent based on the Crossref metadata was lower than the impact factors calculated based on Scopus and the Web of Science Core Collection because journals inconsistently deposited reference metadata in Crossref. Korea, the United States, and China have been found to be most common countries of citing authors in most medical journals in Korea (Fig. 5) [15]. This trend simply originates from the fact that the United States and China are the most productive countries in the literature databases at present.

The authors of Ultrasonography most frequently cited Radiology, American Journal of Roentgenology, Journal of Ultrasound Medicine, Ultrasound Medicine and Biology, and European Radiology (Fig. 7). Ultrasonography most frequently received citations from Ultrasound in Medicine and Biology, Journal of Ultrasound in Medicine, Korean Journal of Radiology, and European Radiology (Fig. 6). Of note, Radiology and American Journal of Roentgenology were cited by Ultrasonography frequently. However, the authors who published in those two journals did not cite Ultrasonography to a similar extent. These findings can be interpreted as indicating that the content of Ultrasonography was of interest for authors publishing in the abovelisted most frequently citing journals. 
The type of references should be added when producing JATS XML and Crossref XML. It was possible to trace reference types from those XML files. The authors of Ultrasonography cited journals most frequently (97.2\%). In general, in Korean medical journals, citations of scholarly journals are most frequent than citations of other types of sources [16]. The findings for Ultrasonography are compatible with other journals regarding this phenomenon.

\section{Comparison with Previous Studies}

The present bibliometric results are comparable to those reported in earlier studies of other local journals. As noted in a previous study, "Out of 181 articles of Infection \& Chemotherapy published between 2015 and 2018. There were 196 source journal titles that cited Infection \& Chemotherapy in the 2015-2018 issues. The Hirsch index was 15" [17]. Furthermore, "The number of citable articles of Blood Research from 2013 to 2017 was 196. The number of citing journals in Web of Science Core Collection was 422." In 2016, the Hirsch index of Blood Research based on the Web of Science Core Collection was 10 [18]. In a third journal, it was noted that "From 2012 to 2017, there were 282 citable articles of Clinical Molecular Hepatology. The citing authors were from 85 countries, and their papers had been cited in 663 journals. The Hirsch index was 19" [19]. Thus, the bibliometric results of Ultrasonography are comparable to those of the above three journals.

\section{Comparison with Other International Journals with Related Scope}

Five journals with a scope including ultrasonography or ultrasound and a JCR ranking in the first and second quartiles were present in the 2018 JCR category of Radiology, Nuclear Medicine, and Medical Imaging (Table 3). Only two of those journals showed a higher impact factor than the estimated 2019 impact factor of Ultrasonography. Those five journals are published by commercial publishing companies located in Western Europe and North America, making Ultrasonography the only society-owned journal among the high-ranking journals in this category. Furthermore, there is still no author-side submission fee or article processing charge, although it is a gold open access journal. Therefore, Ultrasonography will be able to continue devoting itself to the wide propagation of highquality information throughout the world without imposing any hindrances on authors.

\section{Limitation and Suggestion for Further Development}

There was no limitation in the bibliometric analysis of the journal because there was no loss of any relevant data.

What next steps or strategies should be taken for the journal to develop further into a top-tier journal in the ultrasonography field?
Table 3. Five SCIE journals in the first and second quartiles of the 2018 JCR ranking in the category of Radiology, Nuclear Medicine, and Medical Imaging in comparison with Ultrasonography

\begin{tabular}{|c|c|c|c|}
\hline Journal title & IF (2 years) & Publisher & Country \\
\hline $\begin{array}{l}\text { Ultrasound in Obstetrics \& } \\
\text { Gynecology }\end{array}$ & 5.595 & Wiley & USA \\
\hline $\begin{array}{l}\text { Ultraschall in der Medizin } \\
\text { - European Journal of } \\
\text { Ultrasound }\end{array}$ & 4.613 & $\begin{array}{l}\text { Georg Thieme } \\
\text { Verlag }\end{array}$ & Germany \\
\hline Ultrasonography & $3.20^{\mathrm{a})}$ & $\begin{array}{l}\text { Korean Society } \\
\text { of Ultrasound } \\
\text { in Medicine }\end{array}$ & Korea \\
\hline Ultrasonics & 2.598 & Elsevier & Netherlands \\
\hline Ultrasonic Imaging & 2.49 & SAGE & USA \\
\hline $\begin{array}{l}\text { Ultrasound in Medicine and } \\
\text { Biology }\end{array}$ & 2.205 & Elsevier & England \\
\hline
\end{tabular}

SCIE, Science Citation Index Expanded; JCR, Journal Citation Reports.

${ }^{a)}$ Estimated 2019 impact factor (IF).

First, I suggest adopting a data-sharing policy for all types of articles other than clinical trials. Openly sharing data with other researchers has the following benefits: guaranteeing reproducibility, ensuring reliable scientific soundness, facilitating subsequent metaanalyses or mega-analyses, and resource-saving by avoiding the need to reproduce the same data [20]. In Korea, there are still only a few journals that have adopted a data-sharing policy. The results of a 2019 survey of 100 journals showed that 13 had adopted such a policy, with repository sites including Harvard Dataverse (2) and Mendeley Data (1) [21]. There is a Korean journal that mandates data sharing and peer-reviews data [22]. Adoption of a data-sharing policy will be beneficial for strengthening the transparency of the articles published in Ultrasonography.

Second, Ultrasonography should be added to MEDLINE. Although Ultrasonography has been searchable in PubMed since 2014 as a PMC journal, being indexed in MEDLINE would provide the following additional benefits: first, Medical Subject Heading terms would be added to the abstracts in PubMed, thereby enabling more specific search results; and second, it would enhance Ultrasonography's branding to have been acknowledged by the reviewers of the United States National Library of Medicine Literature Selection Technical Review Committee (LSTRC) [23]. During review by LSTRC, 3 points are usually checked: quality of the journal, importance to a variety of readers, and ethics policies/adherence.

Quality is checked in terms of the journal's "scientific merits (validity, the currency of information and references, originality, contribution to the field), editorial works (credibility of contents), and production quality (layout, printing, readability, usability, graphics; number and location of advertisements)" [23]. Scientific 
quality is a somewhat challenging criterion, although it can be determined by a specialist in the same field or a related field. Contribution to the field may be reflected by the citation frequency by other researchers. However, the editorial works and production quality of Ultrasonography are excellent in comparison to other MEDLINE-indexed journals. The main readers of the journal are radiologists in the field of ultrasonography in the clinical field. It also publishes some articles relevant for researchers on medical physics. Ultrasonography has already strictly adhered to research and publication ethics standards: to prevent plagiarism or duplicate publications, the editor screens all manuscripts using Crosscheck; patient anonymity is strictly kept; informed consent is obtained from all subjects; and conflicts of interest are declared in all articles $[24,25]$. There is a document indicating that the journal complies with the Principles of Transparency and Best Practice in Scholarly Publishing, 3rd version [26].

Nonetheless, being indexed in MEDLINE is no easy task. The recent passing rate of the MEDLINE review process is around $15 \%$, and only a few medical journals in Korea have successfully been indexed in MEDLINE. However, it is time for the editors of Ultrasonography to do their best to be approved by the LSTRC.

\section{Conclusion}

It can be concluded that the position of Ultrasonography in the scholarly journal network is well-established according to the above bibliometric analyses. Its 2019 JCR ranking will be in the second quartile in the equivalent category; furthermore, it is among the top 3 journals in the ultrasonography field if its estimated 2019 impact factor is considered. The rapid ascent of Ultrasonography was made possible by the devotion of its editors and the unstinting support of the Korean Society of Ultrasound in Medicine. The next step is to improve the quality of articles by adopting a mandatory data-sharing policy. Additionally, becoming a MEDLINE journal will enhance the journal's brand.

ORCID: Sun Huh: https://orcid.org/0000-0002-8559-8640

\section{Conflict of Interest}

The funding institute did not intervene in any work of the present study except by providing financial support. No other potential conflict of interest relevant to this article was reported.

\section{Acknowledgments}

This work was supported by the Hallym University Research Fund (HRF-201909-016).

\section{Supplementary Material}

Supplementary data are available from Harvard Dataverse (https:// doi.org/10.7910/DVN/ZMJN2P).

Supplementary Data 1. Authors' countries of Ultrasonography from 2014 to 2019.

Supplementary Data 2. Total cites of Ultrasonography published from 2014 to 2019 based on the Crossref metadata, Scopus, and Web of Science Core Collection [cited 2020 Mar 16].

Supplementary Data 3. Countries of authors who cited Ultrasonography in publications from 2014 to 2019 based on Web of Science Core Collection [cited 2020 Mar 16].

Supplementary Data 4. Source titles that cited Ultrasonography in publications from 2014 to 2019 [cited 2020 Mar 16].

Supplementary Data 5. Journal titles of references of Ultrasonography in publications from 2014 to 2019.

\section{References}

1. Han JK. Another step toward the global ultrasound community. Ultrasonography 2014;33:2.

2. YU JS. ULTRASONOGRAPHY: on the way to becoming an internationally renowned journal. Ultrasonography 2015;34:1-2.

3. YU JS. ULTRASONOGRAPHY: two years of globalization and the achievement of ESCI status. Ultrasonography 2016;35:1-2.

4. YU JS. ULTRASONOGRAPHY is now in SCIE. Ultrasonography 2019:38:277.

5. Yu JS. ULTRASONOGRAPHY: coping with changes and setting new directions after being listed in SCIE. Ultrasonography 2020;39:1-2.

6. Hirsch JE. An index to quantify an individual's scientific research output. Proc Natl Acad Sci U S A 2005;102:16569-16572.

7. Jeong $\mathrm{GH}$, Huh $\mathrm{S}$. Increase in frequency of citation by SCIE journals of non-Medline journals after listing in an open access full-text database. Sci Ed 2014;1:24-26.

8. Schwarzman AB. Journal Article Tag Suite subset and Schematron: achieving the right balance. Sci Ed 2018;5:2-15.

9. Lammey R. CrossRef tools for small publishers. Sci Ed 2015;2:7985.

10. Lammey R. How to apply CrossMark and FundRef via CrossRef extensible markup language. Sci Ed 2014;1:84-90.

11. Im J. Applying Open Researchers and Contributors ID in scholarly journals. Sci Ed 2015;2:28-31.

12. Chang JH. An introduction to using QR codes in scholarly journals. Sci Ed 2014;1:113-117. 
13. Choi HW, Choi YJ, Kim S. Compliance of "Principles of transparency and best practice in scholarly publishing" in academic society published journals. Sci Ed 2019;6:112-121.

14. Huh S. Updates from 2018: Being indexed in EMBASE, becoming an affiliated journal of the World Federation for Medical Education, implementing an optional open data policy, adopting principles of transparency and best practice in scholarly publishing, and appreciation to reviewers. J Educ Eval Health Prof 2018;15:36.

15. Huh S. Clinical and Experimental Vaccine Research's promotion to internationally competitive journal evidenced by journal metrics. Clin Exp Vaccine Res 2017;6:67-71.

16. Kim SH. Pattern of reference types and impact factors of journals in the Korea Citation Index according to academic discipline. Sci Ed 2015;2:10-13.

17. Huh S. Journal metrics of Infection \& Chemotherapy and current scholarly journal publication issues. Infect Chemother 2018;50:219227.

18. Huh S. How much progress has Blood Research made since the change of the journal title in 2013. Blood Res 2018;53:95-100.

19. Huh S. Journal metrics of Clinical and Molecular Hepatology based on the Web of Science Core Collection. Clin Mol Hepatol
2018;24:137-143.

20. Huh S. Recent trends in medical journals' data sharing policies and statements of data availability. Arch Plast Surg 2019;46:493-497.

21. Kim SY, Yi HJ, Huh S. Current and planned adoption of data sharing policies by editors of Korean scholarly journals. Sci Ed 2019;6:1924.

22. Huh S. Establishment of an open data policy for Journal of Educational Evaluation for Health Professions, appreciation for invited reviewers, and acknowledgement of volunteers who made audio recordings. J Educ Eval Health Prof 2017;14:37.

23. Huh S. Is Diabetes \& Metabolism Journal eligible to be indexed in MEDLINE? Diabetes Metab J 2018;42:472-474.

24. Huh S. How to deal with ethical issues involving animal experiments and identifiable photographs in articles published in Archives of Plastic Surgery. Arch Plast Surg 2017;44:475-476.

25. Huh S. Strengthened research ethics, including patient anonymity and informed consent, in MEDLINE and PubMed Central journals. Arch Craniofac Surg 2018;19:241-242.

26. Huh S. Adherence of the Annals of Pediatric Endocrinology \& Metabolism to the Principles of Transparency and Best Practice in Scholarly Publishing. Ann Pediatr Endocrinol Metab 2018;23:1-3. 